\title{
Nuclear and Wolbachia-based multimarker approach for the rapid and accurate identification of tsetse species
}

\author{
Antonios A. Augustinos ${ }^{1 \dagger}$, Irene K. Meki ${ }^{1 \dagger}$, Guler Demirbas-Uzel ${ }^{1}$, Gisele M. S. Ouédraogo ${ }^{1,2}$, Aggeliki Saridaki ${ }^{3}$, \\ George Tsiamis $^{3}$, Andrew G. Parker ${ }^{1}$, Adly M. M. Abd-Alla ${ }^{1}$ and Kostas Bourtzis ${ }^{{ }^{*}}$
}

\begin{abstract}
Background: Tsetse flies (Diptera: Glossinidae) are solely responsible for the transmission of African trypanosomes, causative agents of sleeping sickness in humans and nagana in livestock. Due to the lack of efficient vaccines and the emergence of drug resistance, vector control approaches such as the sterile insect technique (SIT), remain the most effective way to control disease. SIT is a species-specific approach and therefore requires accurate identification of natural pest populations at the species level. However, the presence of morphologically similar species (species complexes and sub-species) in tsetse flies challenges the successful implementation of SIT-based population control.

Results: In this study, we evaluate different molecular tools that can be applied for the delimitation of different Glossina species using tsetse samples derived from laboratory colonies, natural populations and museum specimens. The use of mitochondrial markers, nuclear markers (including internal transcribed spacer 1 (ITS1) and different microsatellites), and bacterial symbiotic markers (Wolbachia infection status) in combination with relatively inexpensive techniques such as PCR, agarose gel electrophoresis, and to some extent sequencing provided a rapid, cost effective, and accurate identification of several tsetse species.

Conclusions: The effectiveness of SIT benefits from the fine resolution of species limits in nature. The present study supports the quick identification of large samples using simple and cost effective universalized protocols, which can be easily applied by countries/laboratories with limited resources and expertise.
\end{abstract}

Keywords: Glossina, Sterile insect technique, Internal transcribed spacer 1 (ITS1), Integrative taxonomy, Symbiosis

\section{Background}

Tsetse flies are responsible for the cyclic transmission of trypanosomes, causative agents of sleeping sickness or human African trypanosomosis (HAT) in humans and nagana or animal African trypanosomosis (AAT) in livestock $[1,2]$. There are about 31 tsetse fly species and sub-species in Glossina genus (Diptera: Glossinidae), distributed in 37 sub-Saharan African countries. However, only 8-10 of these species are of economic importance [3].

Due to the lack of vaccines against trypanosomes and increasing resistance of the AAT parasites to available

\footnotetext{
* Correspondence: K.Bourtzis@iaea.org

${ }^{\dagger}$ Antonios A Augustinos and Irene K Meki contributed equally to this work.

${ }^{1}$ Insect Pest Control Laboratory, Joint FAO/IAEA Division of Nuclear

Techniques in Food and Agriculture, Vienna International Centre, P.O. Box

100, 1400 Vienna, Austria

Full list of author information is available at the end of the article
}

drugs $[4,5]$, vector control remains the most effective way of managing African trypanosomosis [6]. Some of the vector control strategies that have been applied for the control of trypanosomosis include the use of sequential aerosol technique (SAT) [7], stationery attractive devices, live bait technique and sterile insect technique (SIT) [8-10]. The SIT involves production of large numbers of the target insect species in specialized rearing facilities followed by sterilization of the males by irradiation [11]. The sustained and systematic release of the sterile males over the target area in large numbers out-competes the wild male population for mating with wild females. Mating of mass -produced sterile males with wild females leads to no offspring and subsequent decrease of the targeted population [12]. SIT is a species-specific and environmental friendly control 
method that has been successfully applied for the eradication of a population of Glossina austeni from Unguja Island in Zanzibar [13].

The correct species identification is of crucial importance for successful SIT applications. Several methods have been applied to identify tsetse species, including morphological characters such as external genitalia of males, their habitat requirements and host preference [10]. Based on these characters, the Glossina species are divided into three distinct taxonomic groups: morsitans, palpalis and fusca [14]. However, delimitation of closely related species and/or subspecies remains challenging.

In addition to morphological taxonomic identification of Glossina species, molecular and genetic markers have also been used in the last decades. Nuclear markers, such as ITS1 and ITS2, were reported to distinguish some of the species based on the size and/or specificity of the amplicons, as revealed by both agarose gel electrophoresis and sequencing [15-18]. Microsatellite markers have also been developed for different Glossina species and have provided encouraging results regarding their potential use in phylogenetic analysis and species identification [19-23]. Mitochondrial markers, including cytochrome oxidase 1 (COI), cytochrome oxidase 2 (COII), cytochrome b (CYTB), 16S rRNA, and NADH dehydrogenase 2 (ND2), have also been implemented for the phylogenetic analysis of Glossina species, based on DNA sequencing [15-17, 24-27]. The availability of polytene chromosomes in Glossina and the development of polytene chromosome maps provide additional genetic tools that can shed light on specific chromosomal banding pattern changes and / or rearrangements that could provide diagnostic characters for species identification [28-31].

A previously neglected parameter regarding speciation is the development of intimate relationships of the tsetse fly with bacterial symbionts, such as Wigglesworthia glossinidia, Sodalis glossinidius, and Wolbachia, that may alter the host's behavior [32-35]. Wolbachia is obligatory intracellular and maternally transmitted and is known to cause reproductive alterations and cytoplasmic incompatibility $(\mathrm{CI})$ [36]. CI is mainly expressed as embryonic mortality when an infected male mates with an uninfected female (unidirectional CI) [37] or when the male and female crossed harbor different and mutually incompatible Wolbachia strains (bidirectional CI) [38]. Such incompatibilities lead to restriction of gene flow among natural populations and can be both 'accelerators' and diagnostic markers of speciation [39]. Another aspect of symbiosis that could be exploited is the presence of ancient, species-specific, horizontal gene transfer events in the host's chromosomal DNA. Such events have been demonstrated in Glossina, through the presence of fixed chromosomal introgressions of Wolbachia (only in Glossina morsitans morsitans up to now) and can provide additional diagnostic markers [40, 41].
Regarding the delimitation of closely related species and given that speciation can be driven through different or combined forces, integrative taxonomy suggests the utilization of multidisciplinary approaches for the inference of robust conclusions regarding species limits and phylogenetic relationships [42-46]. The utilization of a single marker, or a single class of tightly linked markers (such as mitochondrial genes), although easy to universally apply, is not expected to provide beyond doubt species identification $[47,48]$. The fact that the phylogenetic signal of mitochondrial markers can be masked or altered by the presence of reproductive symbionts, such as Wolbachia (through, for example, mitochondrial sweeps) and the limitation that mitochondrial markers are unable to identify hybrids among closely related species (important in hybridizing zones of closely related species) also points to the need for 'the more, the better' approaches in species delimitation [49]. Previous studies also in tsetse flies have documented that different classes of markers may provide either a differential depth of analysis or even contradicting results $[15,17,50]$.

Besides robustness, it is critical to develop diagnostic tools that can be applied quickly, easily, massively and cost effectively. This can be done by integrating different classes of markers and by utilizing different resolution techniques, such as gel electrophoresis and sequencing. Such integrated approaches allow the screening of many samples and many individuals per sample with reduced cost in a relatively short time and without the need of highly specialized equipment/skills.

Here we report the evaluation of different classes of molecular markers (nuclear ITS1, nuclear microsatellites, mitochondrial genes, and the Wolbachia infection status) for the identification of tsetse taxa. We evaluated these tools against tsetse laboratory colonies that were used as reference material. At the same time, we correlated our data with previously published sequences and data from tsetse museum specimens. Finally, we evaluated the discriminative power of ITS 1 amplicon electrophoresis through the genotyping of an extended collection of samples derived from nature. The main goal of this study was to develop a set of markers and analytical approaches that can quickly and cost effectively support the morphometric taxonomy or even stand alone to identify Glossina species.

\section{Methods \\ Material used \\ Laboratory colonies}

Glossina species maintained at the Insect Pest control Laboratory (IPCL) of the Joint FAO/IAEA Programme of Nuclear Applications in Food and Agriculture (NAFA) were used in this analysis. The species were Glossina pallidipes, G. morsitans morsitans, G. morsitans centralis, G. palpalis gambiensis, G. fuscipes fuscipes, and G. brevipalpis. 
Table 1 Glossina samples analyzed in this study

\begin{tabular}{|c|c|c|c|c|c|}
\hline Glossina species & Collection site & $\begin{array}{l}\text { Original } \\
\text { collection date }\end{array}$ & Details & Origin $^{a}$ & N \\
\hline \multirow[t]{2}{*}{ G. pallidipes } & Uganda (Tororo) & 1975 & $\begin{array}{l}1978 \text { IPCL (from Institute of Experimental } \\
\text { Entomology, Amsterdam, The Netherlands) }\end{array}$ & L & 8 \\
\hline & Ethiopia (Arba Minch) & $1997-2001$ & 2005 IPCL (Arba Minch colony) & L & 8 \\
\hline G. m. morsitans & Zimbabwe & 1968 & 1972 IPCL (from Bristol laboratory colony) & $L$ & 8 \\
\hline G. m. centralis & Tanzania & N/A & 1999 IPCL & $\mathrm{L}$ & 8 \\
\hline \multirow[t]{2}{*}{ G. p. gambiensis } & Burkina Faso & 1972 & 2005 IPCL (from CIRDES laboratory colony) & L & 8 \\
\hline & Senegal (Pout) & 2009 & $2009 \mathrm{IPCL}$ & L & 8 \\
\hline G. f. fuscipes & Central Africa Republic & 1986 & $2009 \mathrm{IPCL}$ & $L$ & 8 \\
\hline G. brevipalpis & Kenya (Shimba hills) & 1987 & $2002 \mathrm{IPCL}$ & L & 8 \\
\hline G. tachinoides & Burkina Faso & N/A & CIRDES & L & 12 \\
\hline G. m. submorsitans & Burkina Faso & N/A & CIRDES & L & 12 \\
\hline total & & & & & 88 \\
\hline \multirow[t]{3}{*}{ G. m. morsitans } & $\begin{array}{l}\text { Tanganyika Terr } \\
\text { (Morogoro, Uluguru) }\end{array}$ & 1915 & Dr. A. G. Wilkins & M & 1 \\
\hline & $\begin{array}{l}\text { Tanganyika } \\
\text { (Korogwed Handeni) }\end{array}$ & 1952 & 16-IX-52 Brit. Mus. 1959-638 Dr. E. Burtt & M & 1 \\
\hline & $\begin{array}{l}\text { Tanganyika Terr: } \\
\text { (Morogoro, Uluguru) }\end{array}$ & 1921 & $\begin{array}{l}\text { Dr. A.G. Wilkins Pres. by Imp. Bur. Ent. Brit. } \\
\text { Mus. 1921-152. }\end{array}$ & M & 2 \\
\hline \multirow[t]{2}{*}{ G. m. centralis } & Tanganyika Terr. & 1923 & Brit. Mus. 1923-269 & M & 1 \\
\hline & $\begin{array}{l}\text { Sedamara } \\
\text { (Mbulu) }\end{array}$ & 1950 & $\begin{array}{l}\text { 26.9.50 London School of Hygiene } \\
\text { \& Tropical Medicine coll. BMNH }\end{array}$ & M & 1 \\
\hline G. p. gambiensis & $\begin{array}{l}\text { Sierra Leone } \\
\text { (Scarcies, Kambia) }\end{array}$ & 1946 & Nash \& Walton, 26/1/46 & M & 1 \\
\hline \multicolumn{5}{|l|}{ total } & 7 \\
\hline \multirow[t]{7}{*}{ G. pallidipes } & Ethiopia (Arba Minch) & 2014 & & $\mathrm{~F}$ & 30 \\
\hline & Uganda (Lukoma - Bavuma) & 2013 & & $\mathrm{~F}$ & 27 \\
\hline & Kenya (BioRI-KALRO) & 2008 & & $\mathrm{~F}$ & 3 \\
\hline & Zambia (Mfuwe) & 2007 & & $\mathrm{~F}$ & 3 \\
\hline & Zimbabwe (Ruckomechi) & 2006 & & $\mathrm{~F}$ & 3 \\
\hline & Zimbabwe (Makuti) & 2006 & & $\mathrm{~F}$ & 1 \\
\hline & Tanzania (Tanga) & 2005 & & $\mathrm{~F}$ & 2 \\
\hline \multirow[t]{5}{*}{ G. m. morsitans } & Zambia (Mfuwe) & 2007 & & $\mathrm{~F}$ & 1 \\
\hline & Zimbabwe (Ruckomechi) & 2006 & & $\mathrm{~F}$ & 1 \\
\hline & Zimbabwe (Makuti) & 2006 & & $F$ & 1 \\
\hline & Tanzania (Usinge) & 2013 & & $\mathrm{~F}$ & 9 \\
\hline & Kenya (BioRI-KALRO) & 2008 & & $F$ & 1 \\
\hline \multirow[t]{2}{*}{ G. m. centralis } & Angola (Guissakina) & 2013 & & $\mathrm{~F}$ & 25 \\
\hline & Tanzania (Ugalla) & 2013 & & $\mathrm{~F}$ & 60 \\
\hline G. m. submorsitans ${ }^{b}$ & Burkina Faso (Comoe) & 2009 & & $\mathrm{~F}$ & 277 \\
\hline \multirow[t]{7}{*}{ G. p. gambiensis ${ }^{b}$} & Senegal (Sebikotane) & 2009 & & F & 3 \\
\hline & Senegal (Sebikotane) & 2013 & & $\mathrm{~F}$ & 9 \\
\hline & Senegal (Kayar) & 2010 & & $\mathrm{~F}$ & 3 \\
\hline & Senegal (Kayar) & 2013 & & $\mathrm{~F}$ & 17 \\
\hline & Senegal (Niokolo-Koba) & 2012 & & $\mathrm{~F}$ & 3 \\
\hline & Senegal (Niokolo-Koba) & 2013 & & $\mathrm{~F}$ & 30 \\
\hline & Senegal (Pout) & 2009 & & $F$ & 11 \\
\hline
\end{tabular}


Table 1 Glossina samples analyzed in this study (Continued)

\begin{tabular}{|c|c|c|c|c|}
\hline Glossina species & Collection site & $\begin{array}{ll}\text { Original } & \text { Details } \\
\text { collection date }\end{array}$ & Origin $^{a}$ & $N$ \\
\hline & Senegal (Pout) & 2013 & $\mathrm{~F}$ & 30 \\
\hline & Burkina Faso (Comoe) & 2008 & $\mathrm{~F}$ & 1152 \\
\hline & Mali & 2010 & $\mathrm{~F}$ & 8 \\
\hline & Guinea & 2010 & $\mathrm{~F}$ & 1 \\
\hline \multirow[t]{2}{*}{ G.f. quanzensis } & Angola (Guissakina) & 2013 & $\mathrm{~F}$ & 3 \\
\hline & Uganda & 2013 & $\mathrm{~F}$ & 52 \\
\hline G. brevipalpis & Mozambique (Maputo GR) & 2013 & $\mathrm{~F}$ & 6 \\
\hline G. swynnertonib & Tanzania (Ikorongo GR) & 2015 & $\mathrm{~F}$ & 24 \\
\hline G. medicorum & Burkina Faso (Comoe) & 2009 & $\mathrm{~F}$ & 86 \\
\hline \multirow[t]{2}{*}{ G. tachinoides $^{b}$} & Burkina Faso (Comoe) & 2009 & $\mathrm{~F}$ & 792 \\
\hline & Ghana & 2009 & $\mathrm{~F}$ & 7 \\
\hline \multirow[t]{4}{*}{ G. austeni } & Mozambique (Maputo G) & 2013 & $\mathrm{~F}$ & 7 \\
\hline & Tanzania (Jozani) & 1994 & $\mathrm{~F}$ & 1 \\
\hline & Zanzibar (Unguja island) & 1995 & $\mathrm{~F}$ & 5 \\
\hline & South Africa (Zululand) & & $\mathrm{F}$ & 1 \\
\hline total & & & & 2695 \\
\hline
\end{tabular}

$N$ Number of specimens tested

N/A not available, CIRDES Centre International de Recherche-Développement sur l'Elevage en zone Subhumide, Bobo Dioulasso, Burkina Faso, IPCL Insect Pest Control Laboratory

aType: $\mathrm{L}=$ Laboratory colony; $\mathrm{M}=$ Museum specimen; $\mathrm{F}=$ Field collection

${ }^{b}$ these collections included false assigned individuals (see also Table 4)

Identification of the fly samples to species was based on standard morphological characters [14]. As morphological characters are not reliable for subspecific identification, the subspecific laboratory colonies were assigned based on the conventional designation for the place of origin. Details of the Glossina species and colonies used in this study are provided in Table 1. All the tsetse colonies are fed on heated, defibrinated bovine blood for 10-15 min, three days per week using an in vitro membrane feeding technique [51].

\section{Museum specimens}

Glossina specimens were obtained from Mr. Nigel P. Wyatt, Department of Entomology, Natural History Museum, London, UK (loan no. 2011-159) and comprised of representatives of the following Glossina taxa: G. morsitans morsitans, G. morsitans centralis, and G. palpalis gambiensis. These specimens were collected between 1915 and 1952 and were assigned to the respective taxa based on morphological characters (Table 1).

\section{Natural populations}

A total of 2634 individual tsetse flies, representing 30 taxon/geographical locations combinations from five countries in West Africa (Burkina Faso, Ghana Guinea, Mali, and Senegal), were included in this analysis. These samples were collected in different periods from 1994 to 2014
(Table 1) and were used as a 'blind test' to verify their species status using the ITS1 PCR amplicons, plus the Wolbachia infection, where necessary/applicable.

\section{DNA extraction, PCR, and sequencing}

Flies derived from laboratory colonies and natural populations

DNA from teneral adult flies of each laboratory colony was isolated using the Qiagen DNeasy kit (Qiagen, Valencia, CA), following the manufacturer's instructions. DNA samples were stored at $4{ }^{\circ} \mathrm{C}$ until their use and at $-20{ }^{\circ} \mathrm{C}$ for long term. Samples collected from the field were sorted by species, labelled, kept in 95\% ethanol (or propylene1,2-diol), and shipped to the IPCL for downstream analysis. DNA extraction was performed as described for the laboratory colonies. For all PCR amplifications, $1.1 \mathrm{X}$ prealiquoted PCR master mix was used (ABgene, UK). In 22.5 $\mu \mathrm{l}$ of the mix, $1.5 \mu \mathrm{l}$ of DNA template and $1 \mu \mathrm{l}$ of forward and reverse primer were added $(10 \mu \mathrm{M}$ each). Nuclear (ITS1 and microsatellite), mitochondrial (COI, 16S rRNA, and $12 \mathrm{~S}$ rRNA), and symbiotic markers (Wolbachia $16 \mathrm{~S}$ $r R N A$ gene) that were used in the present study are shown in Table 2. PCR conditions to amplify COI, 16S rRNA and ITS1 genes were as described previously [16]. Primers 12SCFR and 12SCRR were used to amplify a 377 bp fragment of the $12 S$ rRNA mitochondrial gene, as described in previous publications [52]. PCR conditions to detect the 
Table 2 A list of the molecular markers and primers used in this study

\begin{tabular}{|c|c|c|c|c|c|c|}
\hline Molecular marker & Marker & & Primer name & Primer sequence $5^{\prime}-3^{\prime}$ & Reference & Method of analysis \\
\hline \multirow[t]{6}{*}{ Nuclear markers } & \multirow{2}{*}{\multicolumn{2}{|c|}{ ITS1 }} & GlossinalTS1_for & GTGATCCACCGCTTAGAGTGA & \multirow[t]{4}{*}{ (Dyer et al., 2008) [16] } & \multirow[t]{6}{*}{ Gel electrophoresis } \\
\hline & & & GlossinalTS1_rev & GCAAAAGTTGACCGAACTTGA & & \\
\hline & \multirow{4}{*}{$\begin{array}{l}\text { Microsatellite } \\
\text { markers }\end{array}$} & \multirow[t]{2}{*}{$\mathrm{A} 10$} & $\mathrm{~A} 10 \mathrm{~F}$ & GCAACGCCAAGTGAAATAAAG & & \\
\hline & & & A10 R & TACTGGGCTCGCGTACATAAT & & \\
\hline & & \multirow[t]{2}{*}{ Gmm14 } & Gmm14 F & CACACCCTGGATTACAAA & \multirow[t]{2}{*}{ (Baker \& Krafsur, 2001) [19] } & \\
\hline & & & Gmm14 R & TGAAATGCAACCCTTCTT & & \\
\hline \multirow[t]{6}{*}{$\begin{array}{l}\text { Mitochondrial } \\
\text { markers }\end{array}$} & \multirow{2}{*}{\multicolumn{2}{|c|}{$\mathrm{COI}$}} & $\mathrm{COI}$ & $\begin{array}{l}\text { TTGATTITITGGTCATCCA } \\
\text { GAAGT }\end{array}$ & \multirow[t]{4}{*}{ (Dyer et al., 2008) [16] } & \multirow[t]{6}{*}{ Sequencing } \\
\hline & & & CULR & $\begin{array}{l}\text { TGAAGCTTAAATTCATTGC } \\
\text { ACTAATC }\end{array}$ & & \\
\hline & \multirow{2}{*}{\multicolumn{2}{|c|}{$16 \mathrm{~S}$ rRNA }} & $\mathrm{NI}-\mathrm{J}-12585$ & GGTCCCTTACGAATTTGAATATATCCT & & \\
\hline & & & LR-N-12866 & ACATGATCTGAGTTCAAACCGG & & \\
\hline & \multirow{2}{*}{\multicolumn{2}{|c|}{125 rRNA }} & 12SCFR & GAGAGTGACGGGCGATATGT & \multirow[t]{2}{*}{ (Doudoumis et al., 2012) [52] } & \\
\hline & & & $12 S C R R$ & $\begin{array}{l}\text { AAACCAGGATTAGATACCC } \\
\text { TATTAT }\end{array}$ & & \\
\hline \multirow{2}{*}{$\begin{array}{l}\text { Symbiotic } \\
\text { markers }\end{array}$} & \multirow[t]{2}{*}{ Wolbachia } & \multirow[t]{2}{*}{$16 \mathrm{~S}$ rRNA } & WspecF & YATACCTATTCGAAGGGATAG & & \multirow[t]{2}{*}{ Gel electrophoresis } \\
\hline & & & WspecR & AGCTTCGAGTGAAACCAATTC & & \\
\hline
\end{tabular}

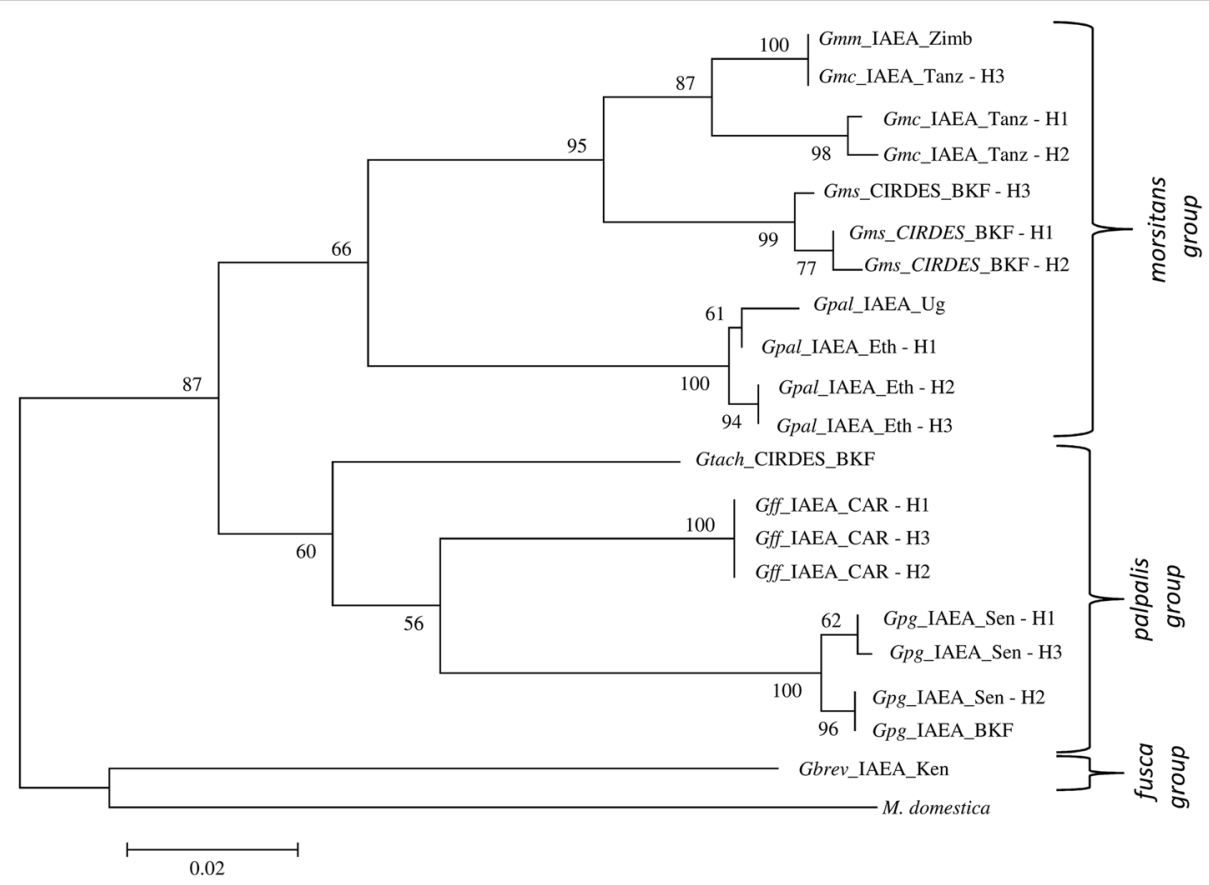

Fig. 1 Molecular Phylogenetic analysis of laboratory populations by Maximum Likelihood method, using a COI gene fragment. The evolutionary history was inferred by using the Maximum Likelihood method based on the Tamura-Nei model. The tree with the highest log likelihood $(-2065.3726)$ is shown. The percentage of trees in which the associated taxa clustered together is shown next to the branches. Initial tree(s) for the heuristic search were obtained automatically by applying Neighbor-Join and BioNJ algorithms to a matrix of pairwise distances estimated using the Maximum Composite Likelihood (MCL) approach, and then selecting the topology with superior log likelihood value. The tree is drawn to scale, with branch lengths measured in the number of substitutions per site. The analysis involved 20 nucleotide sequences. Codon positions included were 1st+2nd+3rd+Noncoding. All positions containing gaps and missing data were eliminated. There was a total of 600 positions in the final dataset. Musca domestica was used as outgroup. The numbers at each node represent bootstrap proportions based on 1000 replications. All abbreviations used in the Figures are shown in Additional file 5. 
Table 3 Analysis of ITS1 sequence length, microsatellite markers and Wolbachia status in Glossina laboratory populations

\begin{tabular}{|c|c|c|c|c|c|c|c|c|}
\hline \multirow[t]{2}{*}{ Glossina species } & \multirow{2}{*}{$\begin{array}{l}\text { Country of } \\
\text { origin (Location) }\end{array}$} & \multirow[t]{2}{*}{ No } & \multirow{2}{*}{$\begin{array}{l}\text { ITS1 expected } \\
\text { size }\end{array}$} & \multicolumn{2}{|l|}{ Wolbachia } & \multicolumn{2}{|c|}{ Microsatellites } & \multirow{2}{*}{$\begin{array}{l}\text { Correctly } \\
\text { identified } \\
\text { samples }\end{array}$} \\
\hline & & & & cytoplasmic & chromosomal & A10 & Gmm14 & \\
\hline \multirow[t]{2}{*}{ G. pallidipes } & $\begin{array}{l}\text { IPCL } \\
\text { Uganda }\end{array}$ & 8 & 920 & $0.0 \%(0 / 8)$ & $0.0 \%(0 / 8)$ & - & + & $8 / 8$ \\
\hline & $\begin{array}{l}\text { IPCL } \\
\text { Ethiopia }\end{array}$ & 8 & & $12.5 \%(1 / 8)$ & $0.0 \%(0 / 8)$ & - & + & $8 / 8$ \\
\hline G. m. morsitans & $\mathrm{IPCL}$ & 8 & 775 & $75 \%(6 / 8)$ & $100 \%(8 / 8)$ & - & + & $8 / 8$ \\
\hline G.m. centralis & $\mathrm{IPCL}$ & 8 & $\sim 800+\sim 150$ & $100 \%(8 / 8)$ & $0.0 \%(0 / 8)$ & - & + & $8 / 8$ \\
\hline G. m. submorsitans & CIRDES & 12 & $\sim 800+\sim 150$ & $0.0 \%(0 / 12)$ & $0.0 \%(0 / 8)$ & - & + & $12 / 12$ \\
\hline \multirow[t]{2}{*}{ G.p. gambiensis } & $\begin{array}{l}\text { IPCL } \\
\text { POUT }\end{array}$ & 8 & 543 & $0.0 \%(0 / 8)$ & $0.0 \%(0 / 8)$ & + & + & $8 / 8$ \\
\hline & $\begin{array}{l}\text { IPCL } \\
\text { CIRDES }\end{array}$ & 8 & & $0.0 \%(0 / 8)$ & $0.0 \%(0 / 8)$ & + & + & $8 / 8$ \\
\hline G. f. fuscipes & $\begin{array}{l}\text { IPCL } \\
\text { Central Africa } \\
\text { Republic }\end{array}$ & 8 & 618 & $12.5 \%(1 / 8)$ & $0.0 \%(0 / 8)$ & Partial & + & $8 / 8$ \\
\hline G. brevipalpis & $\mathrm{IPCL}$ & 8 & 778 & $75 \%(6 / 8)$ & $0.0 \%(0 / 8)$ & - & - & $8 / 8$ \\
\hline G. tachinoides & CIRDES & 12 & 597 & $0.0 \%(0 / 12)$ & $0.0 \%(0 / 8)$ & - & + & $12 / 12$ \\
\hline
\end{tabular}

-: no amplicon detected

$+:$ the expected amplicon was detected in all individuals screened

Partial: the expected amplicon was detected, but not in all individuals screened

presence of cytoplasmic or nuclear Wolbachia 16S rRNA were as described previously using the Wolbachia specific primers wspecF and wspecR [52]. PCR conditions for the different sets of microsatellite markers were as described in the respective publications $[16,19,21,22,53,54]$. PCR products were analysed on $1.5 \%$ agarose gels by electrophoresis and visualized using ethidium bromide. Amplicons of the mitochondrial genes were purified using QIAquick PCR kit (Qiagen Valencia, CA) and sequenced by MWG (MWG-Biotech AG, Germany). Forward and reverse sequences with good quality read were assembled and aligned using SeqMan Pro software (Lasergene 7.0, Dnastar Inc). The consensus sequences for each gene were aligned and trimmed using the ClustalW algorithm in MEGA version 6.0.

\section{Museum specimens}

Before DNA extraction, Glossina specimens were surface-sterilized by immersing in $80 \%$ ethanol and then rinsed with sterile PBS twice. DNA was extracted using Nucleospin Tissue Kit (Macheray-Nagel) following the manufacturer's instructions. DNA integrity was assayed by amplifying part of the mitochondrial 12S rRNA gene as described above. DNA samples were stored at $4{ }^{\circ} \mathrm{C}$ until their use and at $-20{ }^{\circ} \mathrm{C}$ for long term storage. PCR amplifications were performed in reactions containing $10 \mathrm{ng}$ DNA, $10 \mathrm{pmol}$ of each primer, 0.5 units KAPA Taq (KAPA Biosystems), 1x KAPA buffer A (KAPA Biosystems), $0.25 \mathrm{mM}$ deoxynucleotide triphosphate mixture (dNTPs) and water to a final volume of $20 \mu \mathrm{l}$. Amplification was performed in a PTC-200 Thermal Cycler (MJ Research), using the following cycling conditions: $95^{\circ} \mathrm{C}$ for $5 \mathrm{~min}$, followed by $40 \mathrm{cy}-$ cles of $30 \mathrm{~s}$ at $95{ }^{\circ} \mathrm{C}, 30 \mathrm{~s}$ at $54{ }^{\circ} \mathrm{C}, 1 \mathrm{~min}$ at $72{ }^{\circ} \mathrm{C}$ and a final extension of $10 \mathrm{~min}$ at $72{ }^{\circ} \mathrm{C}$. PCR reactions were electrophoresed on a $1.5 \%$ agarose gel. Negative samples were reamplified by PCR using $2 \mu \mathrm{l}$ of the first PCR reaction as template and the same set of primers and conditions for 35 cycles. Positive samples of the first or the second PCR reaction were further analyzed by double stranded sequencing with both forward and reverse primers. A dye terminatorlabelled cycle sequencing reaction was conducted with the BigDye Terminator v3.1 Cycle Sequencing Kit (PE Applied Biosystems). Reaction products were analyzed using an ABI PRISM 310 Genetic Analyzer (PE Applied Biosystems). Gene sequences generated in this study were assembled and manually edited with SeqManII by DNAStar (Lasergene). For each sample, a majority-rule consensus sequence was created.

\section{Phylogenetic analysis}

Phylogenetic analysis was performed using MEGA 6.0 software [55], using Maximum-Likelihood (ML) based on the General Time Reversible model with gamma distributed rates with 1000 bootstrap replications. Musca domestica (L.) sequences, which are closely related to Glossina genus, were used as outgroup for each of the analysed genes (gi|514058521, COI; AY573084.1, 12S rRNA). 


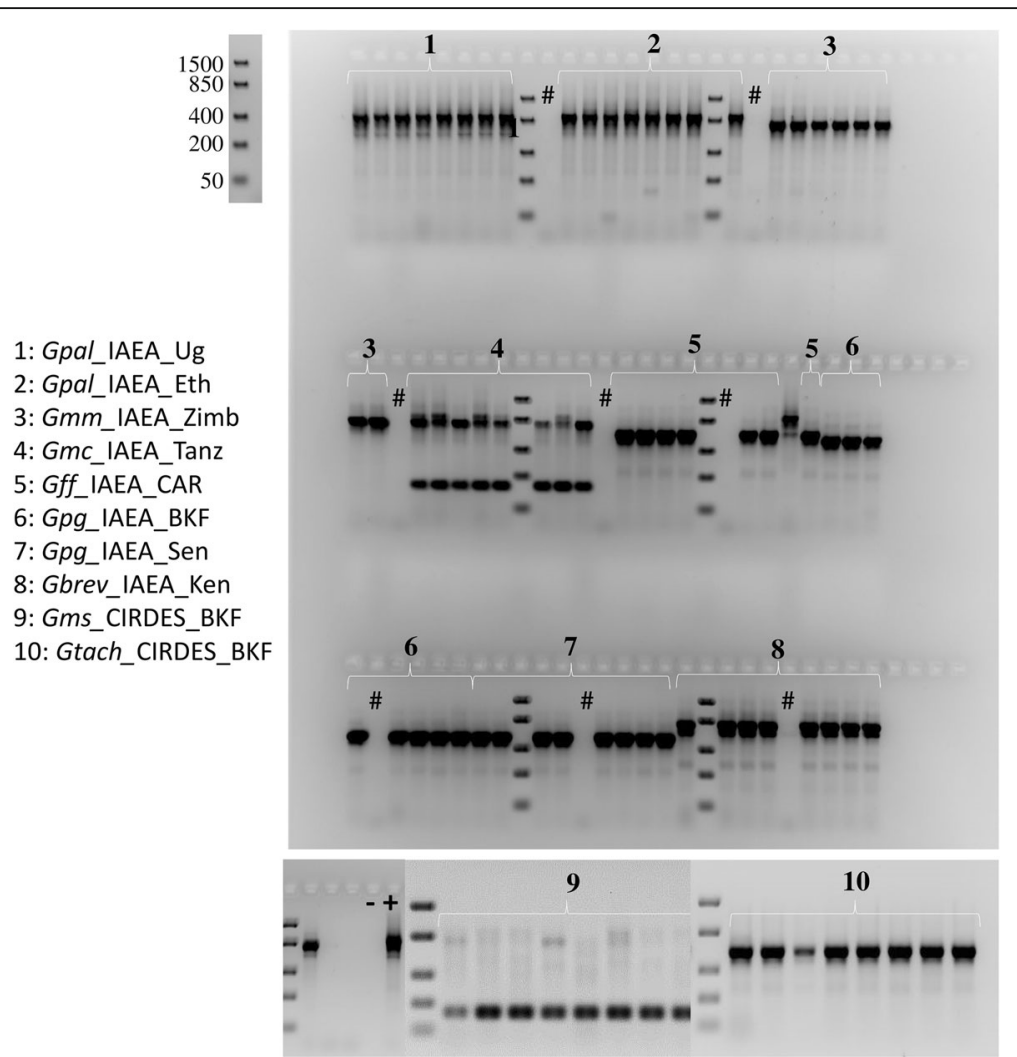

Fig. 2 Agarose gel electrophoresis (2.5\% agarose) showing the ITS1 gene amplicons for the different tsetse laboratory populations. Eight to twelve flies per laboratory population were analyzed. All abbreviations used in the Figures are shown in Additional file 5. The DNA ladder used to determine the size of the analyzed PCR products is also shown. \#: Negative control during DNA extraction; -: negative PCR control; +: positive PCR control (G. pallidipes DNA).

\section{Results}

\section{Evaluation of the discriminating power of different} molecular tools

For the initial evaluation of the available molecular tools, ten laboratory colonies were used and eight to twelve individuals were genotyped per colony (Table 1 ).

\section{Mitochondrial markers: COI and 16S rRNA}

Sequence datasets generated for each of the mitochondrial genes (616 bp for COI and $207 \mathrm{bp} 16 \mathrm{~S} r R N A$ ) were aligned for all ten Glossina laboratory colonies. The phylogenetic reconstruction for each of the mitochondrial markers clearly clustered the three taxonomic groups of Glossina (palpalis, morsitans and fusca groups). COI was more informative than 16s rRNA and was selected as a representative gene of the mitochondrial DNA (Fig. 1). However, clustering in sub species and closely related species level was not always accurate, as in the case of G. m. morsitans and G. m. centralis. Within some taxa, distinct haplotypes were observed using either the COI gene (Fig. 1) or the 16S rRNA gene (data not shown). For instance, G. m. centralis, G. pallidipes from Ethiopia, G. f. fuscipes, and G. p. gambiensis from Senegal were found to have three haplotypes each (H1, H2, H3) for the COI dataset.

\section{Nuclear markers: ITS1 and microsatellite markers}

Variation in the length of the ITS1 amplicon was observed across the different Glossina laboratory colonies, consistent with the species identification (Table 3, Fig. 2, Additional files 1, 2 and 3). Based on size and/or number of amplicons, as revealed by agarose gel electrophoresis, most of the taxa were successfully separated. Among eight screened taxa, only G. m. centralis/G. $m$. submorsitans and G. m. morsitans/G. brevipalpis could not be separated from each other. However, sequencing analysis showed that there was a three bp difference between the amplicons of G. brevipalpis (778 bp) and G. $m$. morsitans (775 bp). This difference can be used to differentiate among them, using higher resolution fragment analysis approaches, such as polyacrylamide gel, low melting agarose or capillary electrophoresis. To further evaluate the discriminative power of ITS1, field collection representing G. swynnertoni (Tanzania) was added in this analysis. This sample shared the ITS1 pattern of the G. m. morsitans/G. brevipalpis group ( 775 bp) (Fig. 2). 
A set of 36 previously published microsatellite markers was tested against 1-3 individuals of the ten laboratory populations (Additional file 1). The analysis was carried out only with agarose gel electrophoresis and showed that there are microsatellite markers producing speciesspecific amplicons in the expected size range. As an example, microsatellite marker A10, which had been designed for G. f. fuscipes and was reported to be specific for G. p. gambiensis, produced the expected amplicon in all G. p. gambiensis specimens plus some of the G. $f$. fuscipes samples but gave no amplicons in all other taxa (Fig. 3a). Also, microsatellite marker Gmm14 amplified in all taxa analyzed except G. brevipalpis (Fig. 3b).

\section{Wolbachia 16S rRNA}

The prevalence of Wolbachia infections differed significantly between the different laboratory colonies (Additional file 4). A fixed cytoplasmic Wolbachia infection (with strong PCR amplicons) was detected only in G. m. centralis. High infection prevalence (with strong PCR amplicons) was observed in G. brevipalpis and G. m. morsitans. Sporadic infections (with weak PCR amplicons) were observed in G. pallidipes and G. f. fuscipes. However, G. m. morsitans presented the fixed chromosomal insertion (296 bp amplicon) previously reported [52] that was present in none of the other laboratory colonies. The remaining taxa/colony (G. $m$. sub-morsitans, G. p. gambiensis, and G. tachinoides) did not give any amplicon indicative of either active cytoplasmic infection or chromosomal insertion of Wolbachia (Table 3, Fig. 4).

\section{Correlation with museum specimens}

Due to low DNA quality, only few amplicons were obtained from museum specimens and only for the $12 \mathrm{~S}$ rRNA gene. Therefore, representative samples from all laboratory colonies were also sequenced for the $12 \mathrm{~S}$ $r R N A$ gene. Despite the limited resolution provided, the laboratory colonies correlated well with the museum specimens (Fig. 5).

\section{Evaluation of $\mathrm{COI}$ as a 'stand-alone' marker for species identification}

COI gene sequence was used to a) correlate our reference laboratory colonies with published sequences of different taxa, and b) identify selected samples from the field that were available in IPCL DNA base. In general, laboratory colonies were well correlated both to previously published sequences (Fig. 6a) and samples field collections available in our DNA base (Fig. 6b). On the other hand, COI cannot clearly resolve closely related species (subspecies or complex species), as was the case of the G. morsitans subspecies and G. f. quanzensis from Angola (which is more closely related to the G. p. gambiensis samples, rather than the rest of the G. fuscipes samples (Fig. 6b).
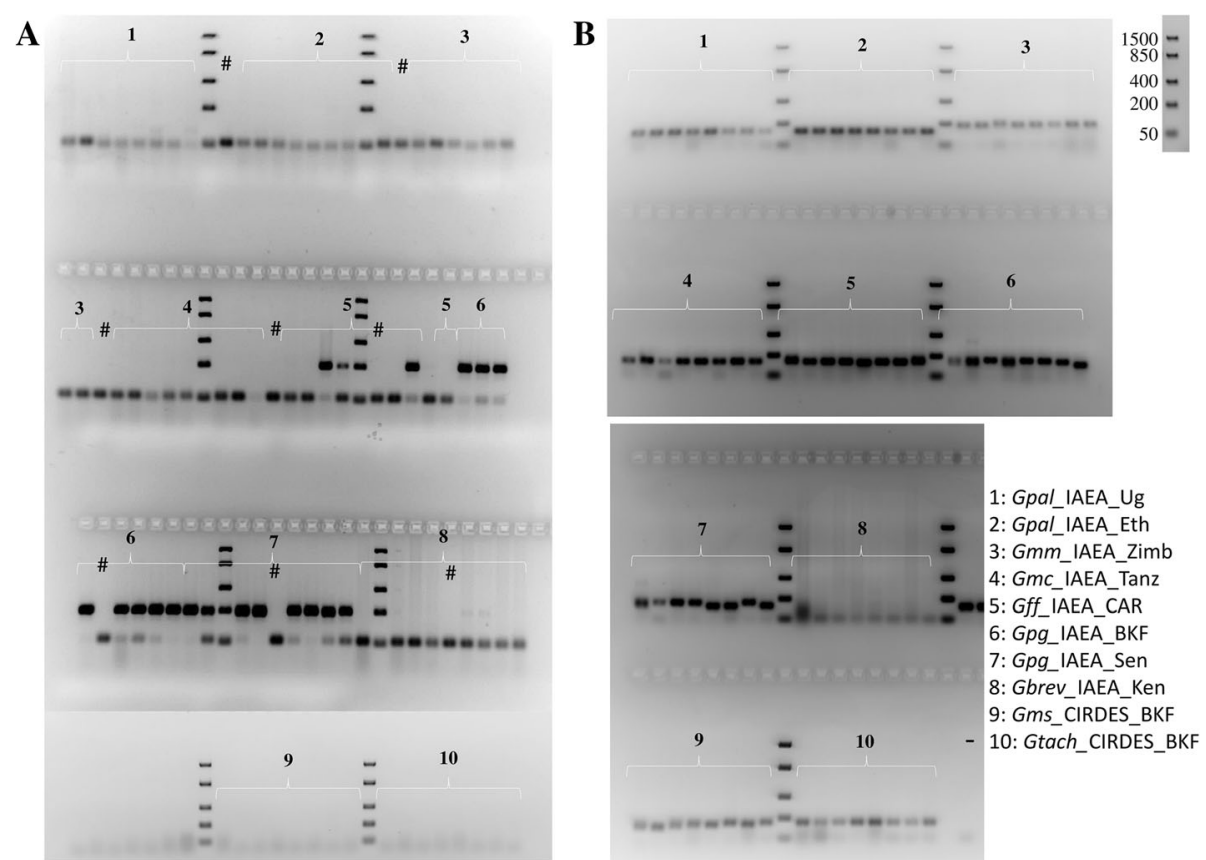

Fig. 3 Agarose gel electrophoresis (2\% agarose) presenting microsatellite markers A10 (a) and Gmm14 (b) amplicons for the different laboratory populations. Eight to twelve flies per laboratory population were analyzed. All abbreviations used in the Figures are shown in Additional file 5 . The DNA ladder used to determine the size of the analyzed PCR products is also shown. \#: Negative control during DNA extraction; -: negative PCR control 


\section{Development of a multi-marker species identification approach}

Based on the initial data derived from the laboratory colonies, we focused on the discriminative power of the combined use of ITS1, microsatellite markers Gmm14/ A10, and the Wolbachia status (both cytoplasmic and chromosomal), utilizing only agarose gel electrophoresis. Previous findings as well as the findings of this study, suggested that the length of the ITS1 amplicon should be sufficient to identify most of the taxa analyzed, except two cases: the G. m. centralis/G. m. submorsitans group and the G. m. morsitans/ G. brevipalpis (Fig. 2). To differentiate G. $m$. centralis from G. $m$. submorsitans, we used the Wolbachia infection status (cytoplasmic) (Fig. 4). To differentiate G. m. morsitans from G. brevipalpis, we used the G. m. morsitans - specific chromosomal introgression of the Wolbachia 16S rRNA gene (Fig. 4). These results are summarized in Table 3 and the approach used to differentiate among the available taxa is summarized in Fig. 7. Following this approach, without using any morphological data, all ten laboratory colonies (representing 8 taxa) were accurately resolved.

\section{The 'blind test' using ITS1, selected microsatellite markers, and Wolbachia}

To further test the resolution power of this combined approach, a 'blind test' of randomly selected DNAs available at the DNA base of the IPCL was performed. The first step was the application of the ITS1 assay. A total of 2695 individuals were genotyped and 2662 (98.78\%) were assigned to the expected taxon (Table 4), based on the information available upon collection. For 33 individuals, there was a discrepancy between data obtained upon collection and ITS1 profile. More specifically, for $0.57 \%$ of the G. p. gambiensis samples (7 out of 1267), $7.94 \%$ of the G. m. submorsitans samples (22 out of 277), $0.13 \%$ of the G. tachinoides samples (1 out of 799), and $12.5 \%$ of the G. swynnertoni samples (3 out of the 24), data from collection sites were not in agreement with the molecular identification (Table 4). These

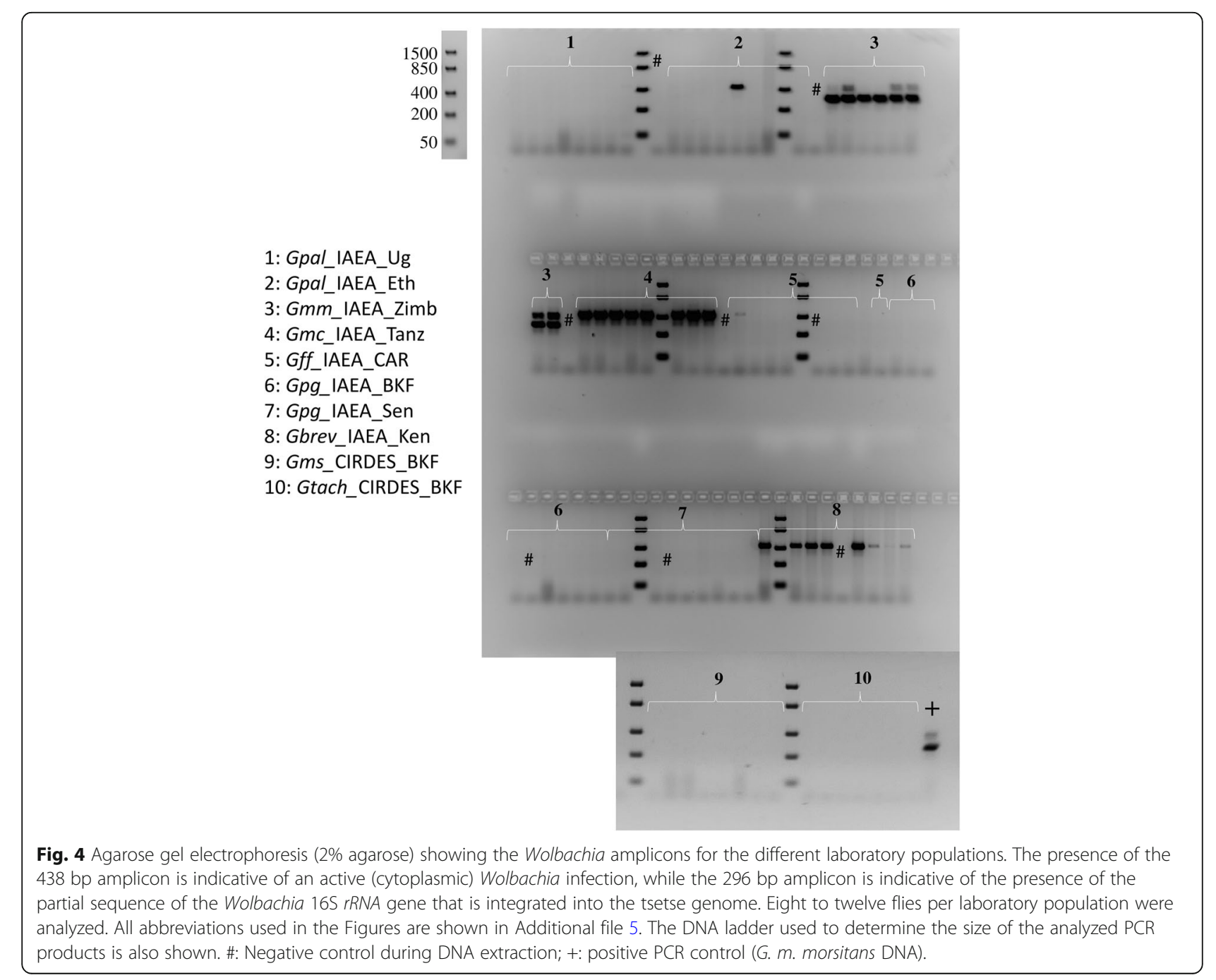




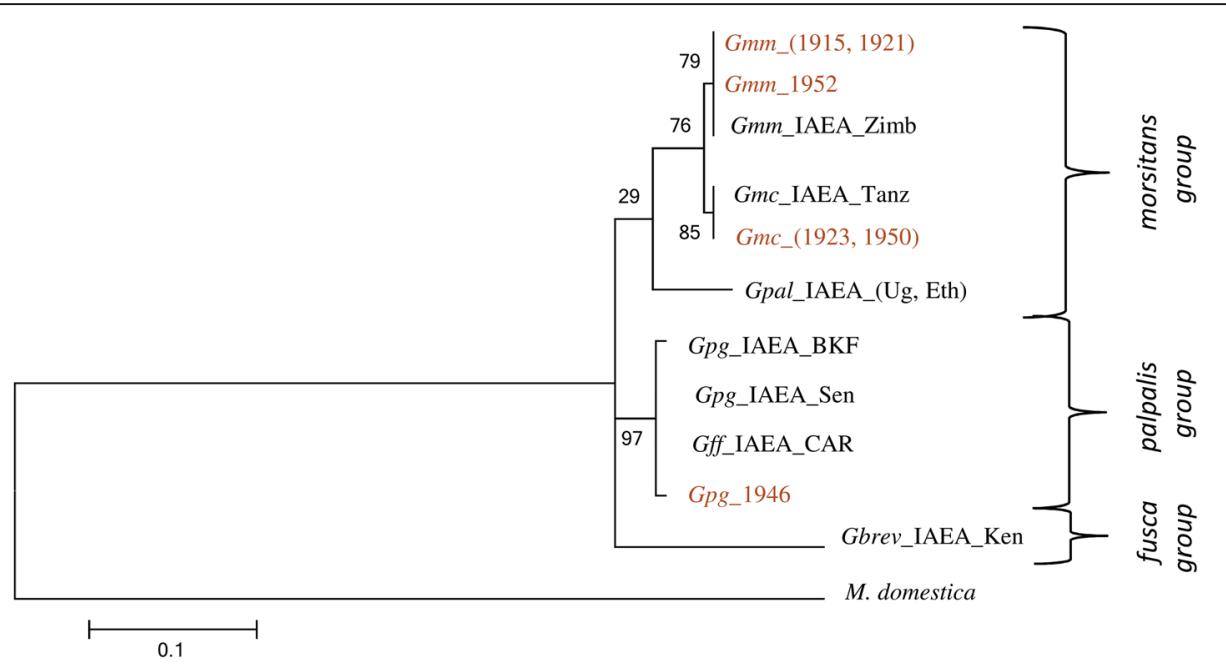

Fig. 5 Molecular Phylogenetic analysis of laboratory populations and museum specimens by Maximum Likelihood analyses, using the $12 S$ rRNA gene sequence. The evolutionary history was inferred by using the Maximum Likelihood method based on the Tamura-Nei model. The tree with the highest log likelihood (-629.9965) is shown. The percentage of trees in which the associated taxa clustered together is shown next to the branches. Initial tree(s) for the heuristic search were obtained automatically by applying Neighbor-Join and BioNJ algorithms to a matrix of pairwise distances estimated using the Maximum Composite Likelihood (MCL) approach, and then selecting the topology with superior log likelihood value. The tree is drawn to scale, with branch lengths measured in the number of substitutions per site. The analysis involved 12 nucleotide sequences. Codon positions included were 1st+2nd+3rd+Noncoding. All positions containing gaps and missing data were eliminated. There was a total of 180 positions in the final dataset. The numbers at each node represent bootstrap proportions based on 1000 replications. Laboratory populations are in black and Museum specimens are in brown. Musca domestica was used as outgroup. All abbreviations used in the Figures are shown in Additional file 5.

samples were revisited and the Wolbachia infection status, the amplicon profile of microsatellite markers A10 and $\mathrm{Gmm} 14$, and the sequencing data of $\mathrm{COI}$ gene were also used. The combined use of the four classes of markers, along with data of the geographical distribution of Glossina species verified the taxon of these samples, showing that they were cases of either misidentification in the field or subsequent mislabeling (Table 4). Therefore, all samples were correctly identified with the combined use of these markers. In this analysis, four field collected samples representing four additional taxa were included (G. austeni, G. f. quanzensis, G. medicorum, and G. swynnertoni). For these taxa, there were no laboratory colonies available to use as reference. The estimated size of ITS1 amplicons were in accordance with that expected from previous studies. The pattern of ITS1 is sufficient to differentiate both G. austeni (amplicon of $633 \mathrm{bp}$ ) from all other taxa of this study, although this amplicon size is very similar to the G. fuscipes amplicon size (633 bp). G. f. quanzensis could not be differentiated from G. f. fuscipes, based on the single agarose gel electrophoresis of the ITS1 amplicon. G. medicorum gave two amplicons, with the one having a size between 600 and $700 \mathrm{bp}$, and the other being close to the one expected from previous studies ( $880 \mathrm{bp}$ ). However, in our samples, the amplicon of lower molecular weight (600 -700 bp) was more robust and consistent than the expected one. G. swynertoni provided a unique combined profile: (a) the COI sequencing data place these samples close to G. m. centralis and G. $m$ morsitans (Fig. 6b, Additional file 5), (b) the ITS1 profile (amplicon size) is similar or identical to G. m. morsitans and G. brevipalpis and (c) the Wolbachia infection status (complete absence of both cytoplasmic and chromosomal amplicons). Due to the lack of reference laboratory colonies, the G. swynertoni samples were not included in the approach described in Fig. 7.

Of special interest is the combined use of ITS1 and Wolbachia to differentiate among the subspecies of $G$. morsitans. As described, G. m. morsitans has a distinct ITS1 profile and the presence of the chromosomal introgression of Wolbachia. G. m. centralis and G. m submorsitans, which share the same characteristic ITS1 pattern, can be differentiated by the presence of an active Wolbachia infection. To support this, 85 field collected individuals belonging to G. m. centralis (Angola and Tanzania), that had the same ITS1 profile, were also $100 \%$ infected with Wolbachia (Table 5). Regarding Wolbachia status of the other field collected samples, G. austeni was 100 $\%$ infected, G. brevipalpis did not show a fixed infection pattern (in a small sample size though with strong PCR amplicons in some of the individuals), and three other taxa also presented non-fixed infection patterns and with weak PCR amplicons (G. f. fuscipes, G. f. quanzensis, and G. p. gambiensis). G. pallidipes did not show any evidence of Wolbachia infection (Table 5). 


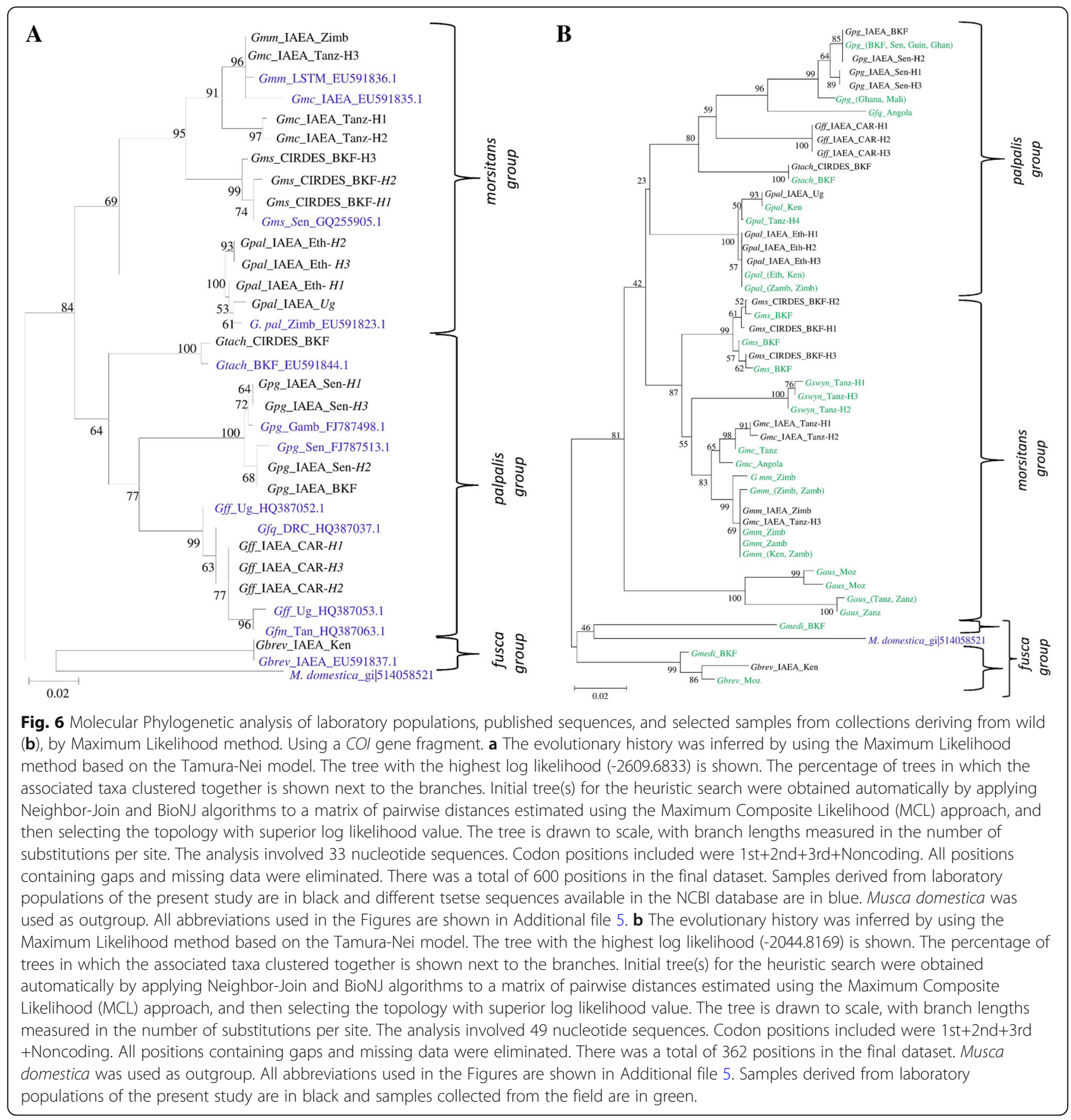

\section{Discussion}

The present study clearly suggests that the combined use of ITS1, selected microsatellite markers, and Wolbachia status (cytoplasmic infection and chromosomal introgression) provides a reliable and cost-effective approach that can be applied for the identification of many Glossina taxa, without need of sequencing.

Sequencing of some of the mitochondrial genes supports the phylogeny of three Glossina groups. Different haplotypes within some species were revealed for the COI gene sequence. Although the sequencing of the mitochondrial markers showed differences among the Glossina species and even within populations of different geographical areas, these sequences alone could not distinguish among some taxa. For instance, the G. m. centralis $H 3$ COI and 16S $r R N A$ gene sequences were similar to the G. m. morsitans sequences. Additionally, mitochondrial markers can be considered as 'compromised' in cases of closely related species. In such cases, mitochondrial haplotypes may have a completely different phylogenetic history than nuclear DNA. Moreover, the distinct patterns of Wolbachia infections in the 


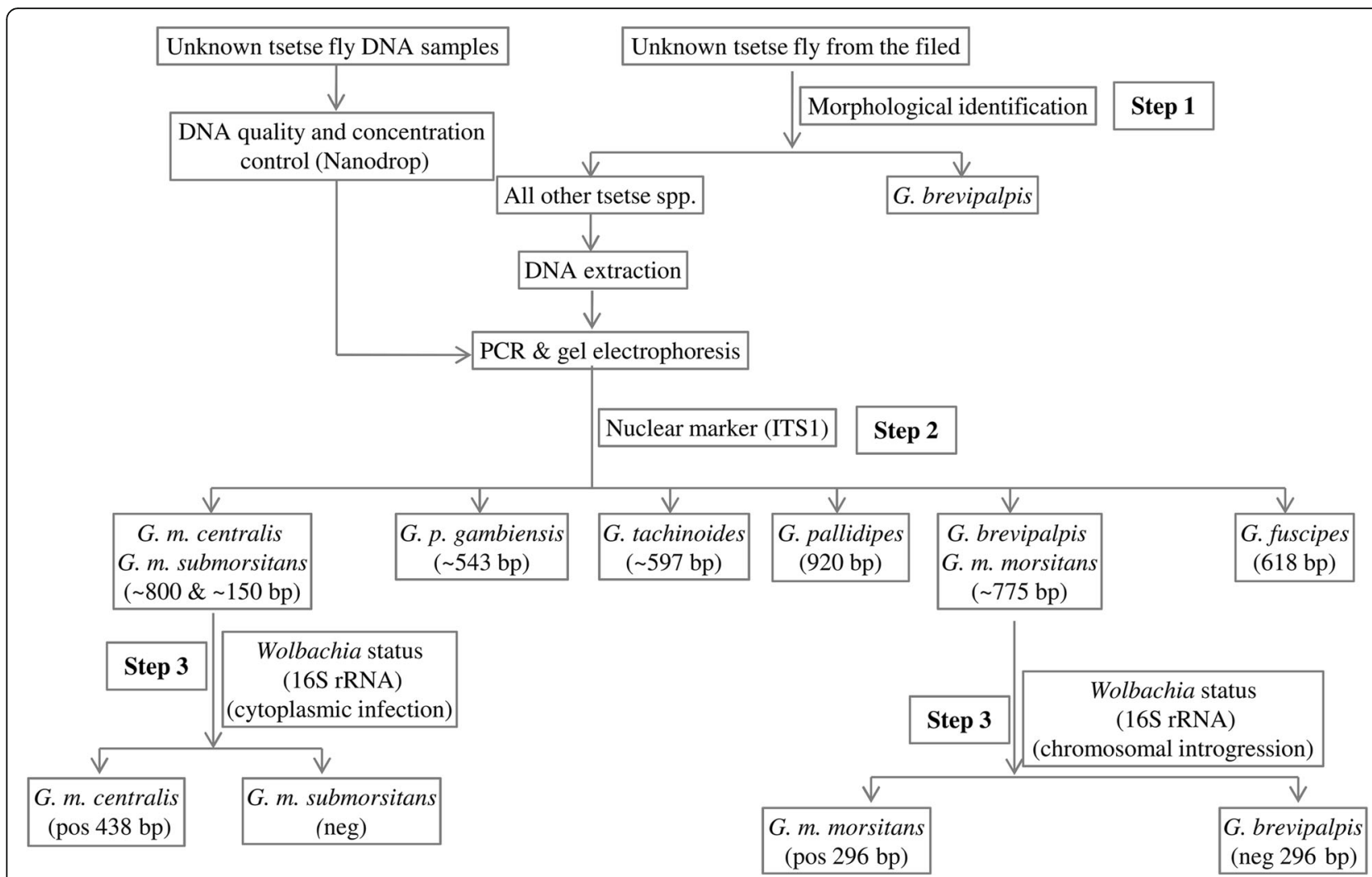

Fig. 7 A multi-marker based approach to distinguish tsetse species, based on agarose gel electrophoresis. This approach relies on the amplicons (size and number) of ITS1 and the presence/absence of the Wolbachia specific 16S rRNA amplicons (both cytoplasmic and chromosomal)

different Glossina taxa make the use of mitochondrial markers even more questionable. For these reasons, sequencing of mitochondrial markers was not included as a tool in the approach followed in the present study.

The ITS1 sequence length variation proved quite a reliable marker in species level. The ITS1 amplicons generated from this study are in accordance with previously published ITS1 sequenced species [15-17] (Additional file 2). Some ITS1 amplicons, representing sequence variants from different taxa (from reference laboratory colonies only), were sequenced to confirm the actual amplicon size (data not shown). In all cases, sequences matched the published ITS1 sequences [16].

Taking together results from laboratory and field samples, the ITS1 amplicon produced eight size variants that could easily be recognized in $2.5 \%$ agarose gel electrophoresis. These profiles successfully identified five species (G. pallidipes, G. p. gambiensis, G. tachinoides, G. austeni, and G. medicorum). The three remaining ITS1 profiles clustered seven taxa in three different groups. The G. m. morsitans / G. swynnertoni / G. brevipalpis group, the G. m. centralis / G. m. submorsitans group, and the G. f. fuscipes / G. f. quanzensis group. To provide further analysis, several microsatellite markers were screened to identify some taxon-specific markers that could be used as diagnostic markers among specific taxa and we coupled this with 'symbiotic markers' that is the Wolbachia status. Cross-species amplification of microsatellite markers is an indication of the phylogenetic relation among different taxa and more closely related taxa are expected to share a higher number of cross amplified markers and this also can be regarded as an indicator of their genetic proximity. This property has been already exploited in Glossina species to avoid the de novo development of markers (Additional file 3). As previously reported [16], microsatellite A10 can be used to distinguish G. p. gambiensis from G. tachinoides which showed similar (but not identical) ITS1 length. Moreover, microsatellite Gmm14 can successfully differentiate G. brevipalpis from all other taxa in this study, which was crucial since it shared an identical (or similar) ITS 1 profile with G. m. morsitans and G. swynnertoni. The two remaining 'black boxes' are the G. m. morsitans / G. swynnertoni and the G. m. centralis / G. m. submorsitans groups. However, based on our (and previous) data, they can be separated based on the Wolbachia profile. G. $m$. morsitans is up to now the only taxon that has a Wolbachia chromosomal insertion that gives a characteristic 16S rRNA amplicon of 296 bp and G. swynnertoni samples tested did not produce this 
Table 4 Validation of Tsetse species from field collected samples using Glossina ITS1

\begin{tabular}{|c|c|c|c|c|c|c|c|c|}
\hline \multirow{2}{*}{$\begin{array}{c}\text { Tsetse field collected } \\
\text { species }\end{array}$} & \multirow{2}{*}{$\begin{array}{l}\text { Expected } \\
\text { band size }\end{array}$} & \multirow{2}{*}{$\begin{array}{l}\text { Tested } \\
\text { flies }\end{array}$} & \multicolumn{2}{|c|}{ Correctly identified flies } & \multicolumn{2}{|c|}{ Misidentified flies } & \multirow{2}{*}{$\begin{array}{l}\text { Band size of the } \\
\text { misidentified samples }\end{array}$} & \multirow{2}{*}{$\begin{array}{c}\text { Corrected } \\
\text { identification }\end{array}$} \\
\hline & & & $\mathrm{N}$ & $\%$ & $\mathrm{~N}$ & $\%$ & & \\
\hline G. pallidipes & 920 & 69 & 69 & 100 & 0 & 0 & - & - \\
\hline G. m. morsitans & 775 & 13 & 13 & 100 & 0 & 0 & - & - \\
\hline G. m. centralis & $800+150$ & 85 & 85 & 100 & 0 & 0 & - & - \\
\hline G.p. gambiensis & 543 & 1267 & 1260 & 99.44 & 7 & 0.56 & $800+150$ & G. m. submorsitans ${ }^{\mathrm{a}}$ \\
\hline G. f. fuscipes & $\sim 618$ & 52 & 52 & 100 & 0 & 0 & - & - \\
\hline G. f. quanzensis & $\sim 618$ & 3 & 3 & 100 & 0 & 0 & - & - \\
\hline G. m. submorsitans & $800+150$ & 277 & 255 & 92.06 & 22 & 7.94 & 597 & G. tachinoides $^{\text {b }}$ \\
\hline G. brevipalpis & 775 & 6 & 6 & 100 & 0 & 0 & - & - \\
\hline G. tachinoides & 597 & 799 & 798 & 99.87 & 1 & 0.13 & $800+150$ & G. m. submorsitans ${ }^{\mathrm{c}}$ \\
\hline G. austeni & $\sim 700$ & 14 & 14 & 100 & 0 & 0 & - & - \\
\hline G. medicorum & $\sim 850+\sim 650$ & 86 & 86 & 100 & 0 & 0 & - & - \\
\hline G. swynnertoni & $\sim 775 \mathrm{bp}^{\mathrm{e}}$ & 24 & 21 & 87.5 & 3 & 12.5 & 920 & G. pallidipes $^{\mathrm{d}}$ \\
\hline total & & 2,695 & 2,662 & 98.78 & 33 & 1.22 & & \\
\hline
\end{tabular}

In grey scale: field collections lacking reference laboratory populations

a Based on the ITS1 profile, non-amplification of microsatellite A10, complete absence of the cytoplasmic infection of Wolbachia, and the geographical distribution of tsetse species, these 7 samples were identified as G. m. submorsitans

${ }^{\mathrm{b}}$ Based on the ITS1 profile, amplification pattern of both A10 and Gmm14 microsatellite markers, absence of cytoplasmic and chromosomal Wolbachia, and the geographic distribution of tsetse species, these individuals were identified as $G$. tachinoides

'Based on the ITS1 profile, amplification of both A10 and Gmm14 microsatellite, absence of cytoplasmic and chromosomal Wolbachia, and the geographic distribution of tsetse species, these individuals were identified as G. m. submorsitans

${ }^{\mathrm{d}}$ Based on the ITS1 profile, COI profile, amplification pattern of both A10 and Gmm14 microsatellite markers, absence of cytoplasmic and chromosomal Wolbachia, and the geographic distribution of tsetse species, these individuals were identified as G. pallidipes

'For G. swynnertoni, there was no ITS1 amplicon expected from previous studies. The one generated in the present study is stated as 'expected'

amplicon. Regarding the last group, G. m. centralis has a fixed Wolbachia infection (cytoplasmic), while G. m. submorsitans seems to lack Wolbachia. Regarding the G. fuscipes subspecies, we did not have well characterized material besides G. f. fuscipes. Few field collected individuals were available for G. $f$. quanzensis that shared the same ITS1 profile with G. $f$. fuscipes. Dyer and her colleagues have developed ITS1 diagnostic primer pairs and diagnostic assays that can differentiate among the three subspecies of G. fuscipes (fuscipes, quanzensis, and martinii) [17]. Since we did not have reference laboratory material for the two of the three subspecies, we could not investigate the identification of these taxa further.
Sequencing of COI gene and presence/absence of microsatellite amplicons of the selected microsatellite markers has not been included in our final combined approach (Fig. 7). COI gene sequencing has been excluded trying to keep the protocol cheap, quick, and easy to apply, taking into account also the reduced credibility of mitochondrial markers for the discrimination of taxa when: (a) there is gene flow among them and (b) there is documented presence of reproductive symbionts, such as Wolbachia. Microsatellite markers have been also excluded for different reasons. Although they gave clear results for selected taxa, we wanted to avoid including markers, which are based on the presence/absence of an

Table 5 Wolbachia status of selected Glossina field collections

\begin{tabular}{|c|c|c|c|c|c|}
\hline \multirow{3}{*}{$\begin{array}{l}\text { Field collected } \\
\text { tsetse species }\end{array}$} & \multicolumn{5}{|c|}{ Wolbachia status } \\
\hline & \multicolumn{3}{|c|}{ Cytoplasmic } & \multicolumn{2}{|c|}{ Chromosomal } \\
\hline & $\bar{N}$ & $\%$ & Estimation & $N$ & $\%$ \\
\hline G. pallidipes & $0 / 57$ & 0 & no PCR amplicon, no infection & $0 / 57$ & 0 \\
\hline G. m. centralis & $85 / 85$ & 100 & strong PCR amplicons, fixed infection & $0 / 85$ & 0 \\
\hline G. p. gambiensis & $15 / 78$ & 19.2 & weak PCR amplicons, sporadic & $0 / 78$ & 0 \\
\hline G. f. fuscipes & $2 / 52$ & 3.8 & weak PCR amplicons, sporadic & $0 / 52$ & 0 \\
\hline G. f. quanzensis & $1 / 3$ & 33.3 & weak PCR amplicons, sporadic & $0 / 3$ & 0 \\
\hline G. brevipalpis & $3 / 6$ & 50 & strong PCR amplicons, not fixed infection & $0 / 6$ & 0 \\
\hline G. austeni & $7 / 7$ & 100 & strong PCR amplicons, fixed infection & $0 / 7$ & 0 \\
\hline
\end{tabular}


amplicon using non-universal primers, since negative results are always difficult to evaluate and classify. Therefore, only the Wolbachia status relies on the presence/ absence of an amplicon using universal Wolbachia $16 \mathrm{~S}$ rRNA gene primers. However, including the microsatellite markers in the analysis can provide redundancy and increased robustness in the interpretation of the data. Moreover, they may be useful for the identification of taxa that have not been included in the present study.

Among the ten laboratory colonies screened here, only G. $m$. centralis harbored a fixed Wolbachia infection and only G. m. morsitans showed a fixed chromosomal insertion. All other laboratory colonies were shown to be either Wolbachia-free (G. pallidipes, G. p. gambiensis, G. $m$. submorsitans, and G. tachinoides) or had varying levels of Wolbachia infection (G. m. morsitans, G. f. fuscipes, and G. brevipalpis). These data are in agreement with previous studies about the Wolbachia infection status of laboratory colonies and natural populations of Glossina species [32, 41, 52, 56, 57]. The presence of Wolbachia in some of the G. pallidipes flies from Ethiopia and its absence from all Uganda G. pallidipes flies suggests that geographical origin of a species might impact the Wolbachia infection status of the species. The presence or absence of Wolbachia infection in the same species from different geographical areas has been previously reported [32, 41, 52, 56]; however, many of these cases are both low prevalence and low titer infections (Additional file 4). The biological, ecological and evolutionary significance of such infections remains to be resolved.

The horizontal gene transfer of Wolbachia was found fixed in G. m. morsitans laboratory colony, using the $16 \mathrm{~S}$ $r R N A$ gene-based PCR assay, in agreement with already published results [40,41]. None of the other laboratory colonies and field collections of any other taxon showed evidence of the specific chromosomal insertion. We did not have material to expand our sampling of G. m. morsitans but all the material belonging to G. $m$. centralis and G. m. submorsitans, both laboratory and field collected, were negative.

\section{Conclusions}

The integration of nuclear and symbiotic markers in this study could clearly discriminate among some different economically important Glossina taxa (Fig. 7). The correct identification at least at the species level is crucial for the application of SIT and requires large numbers of individuals, especially in cases of morphologically indistinguishable subspecies, complexes of species and sympatric species. We avoided using sequencing and/or specialized PCR assays (diagnostic primer pairs) to keep the identification test easy to apply, easy to analyze and of low cost. Although there are now modern tools available that can support molecular taxonomy (genome wide sequencing for example), they cannot yet be used cost effectively on numerous individuals. Therefore, our approach can be considered as adequate to support species identification, especially in African countries where quick decision making and planning may be needed, depending on the data derived from trap collections.

\section{Additional files}

Additional file 1: The set of microsatellites markers tested for the identification of Glossina species. These markers were evaluated against different laboratory populations, considering the amplification of the expected PCR product. (DOCX $19 \mathrm{~kb}$ )

Additional file 2 ITS1 size variants as published in previous studies. (DOCX $17 \mathrm{~kb}$ )

Additional file 3: Microsatellite markers' cross species amplification in different Glossina taxa as referred in previous publications. (DOCX 24 kb)

Additional file 4: Wolbachia status in different Glossina taxa as referred in previous publications. (DOCX $14 \mathrm{~kb}$ )

Additional file 5: Abbreviations used in the Figures (taxon name and country of origin). (DOCX $15 \mathrm{~kb}$ )

\section{Abbreviations}

AAT: Animal African trypanosomosis; Cl: Cytoplasmic Incompatibility; COI: Cytochrome oxidase 1; COII: Cytochrome oxidase 2; CYTB: Cytochrome b; HAT: Human African trypanosomosis; IPCL: Insect Pest Control Laboratory; ITS1: Internal Transcribed Spacer 1; ND2: NADH dehydrogenase 2; PBS: Phosphate Buffer Saline; SAT: Sequential Aerosol Technique; SIT: Sterile Insect Technique

\section{Acknowledgements}

The authors would like to thank Mark Vreysen for his useful comments on the manuscript and his overall support on this study.

\section{Funding}

This work and the publication fees were funded by the Joint FAO/IAEA Division of Nuclear Techniques in Food and Agriculture, IAEA (CRP No.: D4.20.15) Vienna, Austria.

\section{Availability of data and materials}

Sequencing data produced in this study have been deposited in this following link https://dataverse.harvard.edu/ dataset.xhtml?persistentld=doi:10.7910/DVN/2RCDL0

\section{About this supplement}

This article has been published as part of BMC Microbiology Volume 18 Supplement 1, 2018: Enhancing Vector Refractoriness to Trypanosome Infection. The full contents of the supplement are available online at https:// bmcmicrobiol.biomedcentral.com/articles/supplements/volume-18supplement-1.

\section{Authors' contributions}

$\mathrm{AAA}, \mathrm{AMMA}$ and $\mathrm{KB}$ conceived and designed the experiments. AAA, IM, GDU, AS and GOSG performed the experiments. AAA, IM, GT, AP, AMMA, and KB interpreted the experiments. AAA, IM, and GDU drafted the manuscript. AAA, GT, MV, AP, AMMA, and KB have critically revised the manuscript. All authors have approved the version to be published and agreed to be accountable for all aspects of this work.

Ethics approval and consent to participate Not applicable

Consent for publication

Not applicable 


\section{Competing interests}

The authors declare that they have no competing interests.

\section{Publisher's Note}

Springer Nature remains neutral with regard to jurisdictional claims in published maps and institutional affiliations.

\section{Author details \\ ${ }^{1}$ Insect Pest Control Laboratory, Joint FAO/IAEA Division of Nuclear Techniques in Food and Agriculture, Vienna International Centre, P.O. Box 100, 1400 Vienna, Austria. ${ }^{2}$ Ecole National de l'Elevage et de la Santé Animale, 03 BP 7026, Ouagadougou 03, Burkina Faso. ${ }^{3}$ Department of Environmental and Natural Resources Management, University of Patras, Agrinio, Greece.}

\section{Published: 23 November 2018}

\section{References}

1. Aksoy S. Sleeping sickness elimination in sight: Time to celebrate and reflect, but not relax. PLoS Negl. Trop. Dis. 2011;5:e1008.

2. Welburn SC, Fèvre EM, Coleman PG, Odiit M, Maudlin I. Sleeping sickness: A tale of two diseases. Parasitol. Today. 2001;17:19-24.

3. Cecchi G, Mattioli RC, Slingenbergh J, De La Rocque S. Land cover and tsetse fly distributions in sub-Saharan Africa. Med. Vet. Entomol. 2008:22:364-73.

4. Geerts S, Holmes PH, Diall O, Eisler MC. African bovine trypanosomiasis: The problem of drug resistance. Trends Parasitol. 2001;17:25-8.

5. Allsopp R. Control of tsetse flies (Diptera: Glossinidae) using insecticides: A review and future prospects. Bull Entomol Res. 1984;74:1-23.

6. Schofield CJ, Kabayo JP. Trypanosomiasis vector control in Africa and Latin America. Parasite Vector. 2008;1:24.

7. Kgori PM, Modo S, Torr SJ. The use of aerial spraying to eliminate tsetse from the Okavango Delta of Botswana. Acta Trop. 2006;99:184-99.

8. Green CH. Bait methods for tsetse fly control. Adv Parasitol. 1994;34:229-91.

9. Knipling EF. Sterile-Male Method of Population Control: Successful with some insects, the method may also be effective when applied to other noxious animals. Science. 1959;130:902-4.

10. Vreysen MJB, Seck MT, Sall B, Bouyer J. Tsetse flies: Their biology and control using area-wide integrated pest management approaches. J Invertebr Pathol. 2013;112:S15-25.

11. Robinson AS. Genetic Basis of the Sterile Insect Technique. In: Dyck VA, Hendrichs J, Robinson AS, editors. Sterile Insect Tech. Princ. Pract. Area-Wide Integr. Pest Manag. Netherlands: Springer; 2005. p. 95-114.

12. Abila PP, Kiendrebeogo M, Mutika GN, Parker AG, Robinson AS. The effect of age on the mating competitiveness of male Glossina fuscipes fuscipes and $G$. palpalis palpalis. J Insect Sci. 2003;3:1-8.

13. Vreysen MJB, Saleh KM, Ali MY, Abdulla AM, Zhu Z-R, Juma KG, et al. Glossina austeni (Diptera: Glossinidae) eradicated on the Island of Unguja, Zanzibar, using the sterile insect technique. J Econ Entomol. 2000:93:123-35.

14. Pollock JN. Training manual for tsetse control personnel. V. 1: Tsetse biology, systematics and distribution, techniques. Rome: FAO; 1982

15. Dyer NA, Furtado A, Cano J, Ferreira F, Odete-Afonso M, Ndong-Mabale N, et al. Evidence for a discrete evolutionary lineage within Equatorial Guinea suggests that the tsetse fly Glossina palpalis palpalis exists as a species complex. Mol Ecol. 2009;18:3268-82

16. Dyer NA, Lawton SP, Ravel S, Choi KS, Lehane MJ, Robinson AS, et al. Molecular phylogenetics of tsetse flies (Diptera: Glossinidae) based on mitochondrial (COI, 16S, ND2) and nuclear ribosomal DNA sequences, with an emphasis on the palpalis group. Mol Phylogenet Evol. 2008;49:227-39.

17. Dyer NA, Ravel S, Choi K-S, Darby AC, Causse S, Kapitano B, et al. Cryptic diversity within the major trypanosomiasis vector Glossina fuscipes revealed by molecular markers. PLoS Negl Trop Dis. 2011;5:e1266.

18. Chen X, Li S, Li C, Zhao S, Aksoy S. Phylogeny of genus Glossina (Diptera: Glossinidae) according to ITS2 sequences. Sci CHINA Life Sci. 1999;42:249-58.

19. Baker MD, Krafsur ES. Identification and properties of microsatellite markers in tsetse flies Glossina morsitans sensu lato (Diptera: Glossinidae). Mol Ecol Notes. 2001:1:255-7.

20. Ouma JO, Cummings MA, Jones KC, Krafsur ES. Characterization of microsatellite markers in the tsetse fly, Glossina pallidipes (Diptera: Glossinidae). Mol Ecol Notes. 2003:3:450453.
21. Ouma JO, Marquez JG, Krafsur ES. New polymorphic microsatellites in Glossina pallidipes (Diptera: Glossinidae) and their cross-amplification in other tsetse fly taxa. Biochem Genet. 2006:44:471-7.

22. Luna C, Bonizzoni M, Cheng Q, Robinson AS, Aksoy S, Zheng L Microsatellite polymorphism in tsetse flies (Diptera: Glossinidae). J Med Entomol. 2001;38:376-81.

23. Krafsur ES, Endsley MA. Microsatellite diversities and gene flow in the tsetse fly, Glossina morsitans s.l. Med Vet Entomol. 2002;16:292-300.

24. Cordon-Obras C, Cano J, Knapp J, Nebreda P, Ndong-Mabale N, Ncogo-Ada $\mathrm{PR}$, et al. Glossina palpalis palpalis populations from Equatorial Guinea belong to distinct allopatric clades. Parasite Vector. 2014;7:e31.

25. Echodu R, Sistrom M, Hyseni C, Enyaru J, Okedi L, Aksoy S, et al. Genetically distinct Glossina fuscipes fuscipes populations in the lake Kyoga region of Uganda and its relevance for human African trypanosomiasis. Biomed Res Int. 2013:2013:1-12.

26. Marquez JG, Vreysen MJB, Robinson AS, Bado S, Krafsur ES. Mitochondrial diversity analysis of Glossina palpalis gambiensis from Mali and Senegal. Med Vet Entomol. 2004;18:288-95.

27. Solano P, Kaba D, Ravel S, Dyer NA, Sall B, Vreysen MJB, et al. Population genetics as a tool to select tsetse control strategies: Suppression or eradication of Glossina palpalis gambiensis in the niayes of Senegal. PLoS Negl Trop Dis. 2010;4:e692.

28. Gariou-Papalexiou A, Yannopoulos G, Robinson AS, Zacharopoulou A. Polytene chromosome maps in four species of tsetse flies Glossina austeni, G. pallidipes, G. morsitans morsitans and G. m. submorsitans (Diptera: Glossinidae): A comparative analysis. Genetica. 2007;129:243-51.

29. Gariou-Papalexiou A, Yannopoulos G, Zacharopoulou A, Gooding RH. Photographic polytene chromosome maps for Glossina morsitans submorsitans (Diptera: Glossinidae): Cytogenetic analysis of a colony with sex-ratio distortion. Genome. 2002:45:871-80.

30. Pell PE, Southern DI. A cytogenetical study of Glossina fuscipes fuscipes including a comparison of the polytene chromosome maps with those of Glossina austeni (Diptera, Glossinidae). Genetica. 1976;46:511-28.

31. Southern DI, Pell PE. Comparative analysis of the polytene chromosomes of Glossina austeni and Glossina morsitans morsitans. Chromosoma. 1974;47:213-26.

32. Doudoumis V, Blow F, Saridaki A, Augustinos A, Dyer NA, Goodhead I, et al. Challenging the Wigglesworthia, Sodalis, Wolbachia symbiosis dogma in tsetse flies: Spiroplasma is present in both laboratory and natural populations. Sci Rep. 2017;7:e4699.

33. Engl T, Michalkova $V$, Weiss BL, Uzel GD, Takac $P$, Miller WJ, et al. Effect of antibiotic treatment and gamma-irradiation on cuticular hydrocarbon profiles and mate choice in tsetse flies (Glossina m. morsitans). BMC Microbiol. 2018; https:/doi.org/10.1186/s12866-018-1292-7.

34. Hamidou Soumana I, Tchicaya B, Simo G, Geiger A. Comparative gene expression of Wigglesworthia inhabiting non-infected and trypanosoma brucei gambiense-infected Glossina palpalis gambiensis flies. Front Microbiol. 2014;5:e620

35. Wamwiri FN, Alam U, Thande PC, Aksoy E, Ngure RM, Aksoy S, et al. Wolbachia, Sodalis and trypanosome co-infections in natural populations of Glossina austeni and Glossina pallidipes. Parasite Vector. 2013;6:e232.

36. Saridaki A, Bourtzis K. Wolbachia: more than just a bug in insects genitals. Curr Opin Microbiol. 2010;13:67-72.

37. Alam U, Medlock J, Brelsfoard C, Pais R, Lohs C, Balmand S, et al. Wolbachia symbiont infections induce strong cytoplasmic incompatibility in the Tsetse fly Glossina morsitans. PLoS Pathog. 2011;7:1002415.

38. O'Neill SL, Karr TL. Bidirectional incompatibility between conspecific populations of Drosophila simulans. Nature. 1990:348:178-80

39. Shropshire JD, Bordenstein SR. Speciation by symbiosis: The microbiome and behavior. MBio. 2016;7:e01785-15.

40. Brelsfoard C, Tsiamis G, Falchetto M, Gomulski LM, Telleria E, Alam U, et al. Presence of Extensive Wolbachia Symbiont Insertions Discovered in the Genome of Its Host Glossina morsitans morsitans. PLoS Negl Trop Dis. 2014; 8:e2728.

41. Doudoumis V, Alam U, Aksoy E, Abd-Alla AMM, Tsiamis G, Brelsfoard C, et al, Tsetse-Wolbachia symbiosis: Comes of age and has great potential for pest and disease control. J Invertebr Pathol. 2013:112:S94-S103.

42. Dayrat B. Towards integrative taxonomy. Biol J Linn Soc. 2005;85:407-15

43. Fujita MK, Leaché AD, Burbrink FT, McGuire JA, Moritz C. Coalescent-based species delimitation in an integrative taxonomy. Trends Ecol Evol. 2012;27:480-8.

44. Padial JM, Miralles A, De la Riva I, Vences M. The integrative future of taxonomy. Front Zool. 2010;7:e16. 
45. Schutze MK, Aketarawong N, Amornsak W, Armstrong KF, Augustinos AA, Barr $\mathrm{N}$, et al. Synonymization of key pest species within the Bactrocera dorsalis species complex (Diptera: Tephritidae): Taxonomic changes based on a review of 20 years of integrative morphological, molecular, cytogenetic, behavioural and chemoecological data. Syst Entomol. 2015;40:456-71.

46. Schlick-Steiner BC, Steiner FM, Seifert B, Stauffer C, Christian E, Crozier RH. Integrative taxonomy: A multisource approach to exploring biodiversity. Annu Rev Entomol. 2010:55:421-38.

47. Meier R, Shiyang K, Vaidya G, Ng PKL. DNA barcoding and taxonomy in diptera: A tale of high intraspecific variability and low identification success. Syst Biol. 2006;55:715-28.

48. Will KW, Mishler BD, Wheeler QD. The perils of DNA barcoding and the need for integrative taxonomy. Syst Biol. 2005;54:844-51.

49. Kodandaramaiah U, Simonsen TJ, Bromilow S, Wahlberg N, Sperling F. Deceptive single-locus taxonomy and phylogeography: Wolbachia -associated divergence in mitochondrial DNA is not reflected in morphology and nuclear markers in a butterfly species. Ecol Evol. 2013;3:5167-76.

50. Ouma JO, Marquez JG, Krafsur ES. Patterns of genetic diversity and differentiation in the tsetse fly Glossina morsitans morsitans Westwood populations in East and southern Africa. Genetica. 2007;130:139-51.

51. Langley PA, Maly H. Membrane Feeding Technique for Tsetse Flies (Glossina spp.). Nature. 1969;221:855-6.

52. Doudoumis V, Tsiamis G, Wamwiri F, Brelsfoard C, Alam U, Aksoy E, et al. Detection and characterization of Wolbachia infections in laboratory and natural populations of different species of tsetse flies (genus Glossina). BMC Microbiol. 2012;12:S3.

53. Brown JE, Komatsu K, Abila PP, Robinson AS, Okedi LMA, Dyer N, et al. Polymorphic microsatellite markers for the tsetse fly Glossina fuscipes fuscipes (Diptera: Glossinidae), a vector of human African trypanosomiasis. Mol Ecol Resour. 2008;8:1506-8.

54. Solano P, Duvallet G, Dumas V, Cuisance D, Cuny G. Microsatellite markers for genetic population studies in Glossina palpalis (Diptera: Glossinidae). Acta Trop. 1997;65:175-80.

55. Tamura K, Stecher G, Peterson D, Filipski A, Kumar S. MEGA6: Molecular Evolutionary Genetics Analysis version 6.0. Mol Biol Evol. 2013;30:2725-9.

56. Alam U, Hyseni C, Symula RE, Brelsfoard C, Wu Y, Kruglov O, et al. Implications of microfauna-host interactions for trypanosome transmission dynamics in Glossina fuscipes fuscipes in Uganda. Appl Environ Microbiol. 2012;78:4627-37.

57. Symula RE, Alam U, Brelsfoard C, Wu Y, Echodu R, Okedi LM, et al. Wolbachia association with the tsetse fly, Glossina fuscipes fuscipes, reveals high levels of genetic diversity and complex evolutionary dynamics. BMC Evol Biol. 2013;13:e31.

Ready to submit your research? Choose BMC and benefit from:

- fast, convenient online submission

- thorough peer review by experienced researchers in your field

- rapid publication on acceptance

- support for research data, including large and complex data types

- gold Open Access which fosters wider collaboration and increased citations

- maximum visibility for your research: over $100 \mathrm{M}$ website views per year

At BMC, research is always in progress.

Learn more biomedcentral.com/submissions 